\title{
Inhibition of Viability, Proliferation, Cytokines Secretion, Surface Antigen Expression, and Adipogenic and Osteogenic Differentiation of Adipose-Derived Stem Cells by Seven-Day Exposure to 0.5 T Static Magnetic Fields
}

\author{
Jian Wang, ${ }^{1,2,3}$ Bo Xiang, ${ }^{2,4}$ Jixian Deng, ${ }^{2,3}$ Darren H. Freed, ${ }^{2,3,5}$ \\ Rakesh C. Arora, ${ }^{2,3,6}$ and Ganghong Tian ${ }^{2,3}$ \\ ${ }^{1}$ Department of Vascular Surgery, Union Hospital, Tongji Medical College, Huazhong University of Science and Technology, \\ 1277 Jiefang Street, Wuhan, Hubei 430022, China \\ ${ }^{2}$ National Research Council of Canada, 435 Ellice Avenue, Winnipeg, MB, Canada R3B $1 Y 6$ \\ ${ }^{3}$ Department of Physiology, Faculty of Medicine, University of Manitoba, 727 McDermot Avenue, Winnipeg, MB, Canada R3E $3 P 5$ \\ ${ }^{4}$ Department of Pharmacology and Therapeutics, Faculty of Medicine, University of Manitoba, 753 McDermot Avenue, \\ Winnipeg, MB, Canada R3E 0T6 \\ ${ }^{5}$ Division of Cardiac Surgery, University of Alberta Hospital, 8440-112 Street, Edmonton, AB, Canada T6G 2B7 \\ ${ }^{6}$ Cardiac Science Program, Institute of Cardiovascular Science, St. Boniface General Hospital, 409 Tache Avenue, \\ Winnipeg, MB, Canada R2H $2 A 6$
}

Correspondence should be addressed to Jian Wang; jianwang1030@126.com and Ganghong Tian; ganghong.tian@nrc-cnrc.gc.ca Received 7 September 2015; Revised 24 November 2015; Accepted 26 November 2015

Academic Editor: Joost Sluijter

Copyright (C) 2016 Jian Wang et al. This is an open access article distributed under the Creative Commons Attribution License, which permits unrestricted use, distribution, and reproduction in any medium, provided the original work is properly cited.

\begin{abstract}
After seven-day exposure to 0.5-Tesla Static Magnetic Field (SMF), Adipose-derived Stem Cells (ASCs) and those labeled by superparamagnetic iron oxide (SPIO) nanoparticles were examined for viability by methyl thiazol tetrazolium (MTT) assay, proliferation by cell counting and bromodeoxyuridine (BrdU) incorporation, DNA integrity by single cell gel electrophoresis, surface antigen by flow cytometry analysis, and the expression of cytokines and genetic markers by reverse transcription-PCR and underwent adipogenic and osteogenic differentiation assessed by quantifying related specific genes expression. The SMF slightly reduced cell viability and proliferation and inhibited the expression of CD49d, CD54, and CD73 but did not damage DNA integrity. The SMF slightly downregulated the expression of cytokines including Vascular Endothelial Growth Factor (VEGF), Insulin-like Growth Factor-1 (IGF-1), Transforming Growth Factor Beta 1 (TGF- $\beta 1$ ), genetic markers comprising Stem Cell Antigen-1 (Scal), Octamer-4 (Oct-4), ATP-binding Cassette Subfamily B Member 1 (ABCB1), adipogenic marker genes containing Lipoprotein Lipase (LPL), Peroxisome Proliferator-Activated Receptor Gamma (PPAR- $\gamma$ ), and osteogenic marker genes including Secreted Phosphor-protein 1 (SPP1) and Osterix (OSX). Exposure to 0.5 T SMF for seven days inhibited viability, proliferation, surface antigen expression, cytokine secretion, stem cell genetic marker expression, and adipogenic and osteogenic differentiation but did not affect the DNA integrity in ASCs with or without SPIO labeling.
\end{abstract}

\section{Introduction}

Stem cell transplantation is a promising therapeutic approach for ischemic Myocardial Infarction (MI), and its efficiency largely depends on cell homing, retention, and engraftment within the damaged myocardium. Poor cell retention is the major obstacle to achieving a satisfactory functional benefit irrespective of cell type and delivery routes [1-3]. Venous washout and the squeezing effect of cardiac contraction result in substantial cell loss during and immediately after delivery $[4,5]$. Magnetic targeting techniques have been demonstrated to successfully enhance cardiac retention and functional 
benefits of "magnetic" iron-labeled cells via intramyocardial [6], intracoronary [7], intraventricular [8], and intravenous [9] routes to the ischemic hearts.

To track implanted cells in vivo in a noninvasive manner with repeated imaging is advantageous for animal models studies to clarify cell migration, tissue localization, and the longevity of cells following implantation. Superparamagnetic iron oxide (SPIO) particles can generate MRI contrast by disturbing the local Magnetic Field (MF) near excited spins, a property termed $\mathrm{T}_{2}{ }^{*}$ relaxation. SPIO labeling does not affect the biological function and differentiation capacity of Stem Cells (SCs) $[10,11]$. The cells labeled by SPIO can be visualized noninvasively in vivo using MRI serially over a period of weeks [12].

Exposition of SCs to MF is the fundamental principle of MRI tracking and magnetic targeting of implanted cells. Consequently, the influence of Static Magnetic Field (SMF) on biological function of SCs has been becoming a research topic of considerable interest. Most studies have focused primarily on the effects of MF on Bone Marrow Stem Cells (BMSCs). Recently, adipose tissue has emerged as a promising source of SCs for cell-based therapy due to the abundance in most of the population, easy and repetitive harvest with a minimum invasive procedure, and rapid proliferation [13]. Adiposederived Stem Cells (ASCs) can differentiate into endothelial cells and smooth muscle cells, secrete multiple angiogenic cytokines, and eventually improve cardiac function after MI [14-16]. However, less information is available about the effect of SMF on the biological properties of ASCs.

SMF has been categorized according to its induction value as weak $(<1 \mathrm{mT})$, moderate $(1 \mathrm{mT}$ to $1 \mathrm{~T})$, strong $(1-5 \mathrm{~T})$, and ultrastrong $(>5 \mathrm{~T})$. Among these MF strengths, moderate intensity SMF can be easily applied in magnetic targeting or tracking technique and has been shown to affect physiological function in a variety of biological systems. Moreover, timedependent changes in cell structural characteristics with days of exposure to moderate intensity SMF have been reported [17]. Brief exposure to moderate intensity SMF (two days) resulted in slight cellular alteration with return to baseline level within minutes following termination of exposure [17]. The present study was carried out to ascertain whether a prolonged exposure (seven days) to moderate intensity SMF (0.5 T) affect viability, proliferation, apoptosis, DNA structural integrity, surface antigen expression, angiogenic cytokine secretion, stem cell genetic marker expression, and adipogenic and osteogenic differentiation of ASCs and SPIOlabeled ASCs (

\section{Materials and Methods}

This study was approved by the Institutional Review Board and Animal Care Committee of Huazhong University of Science and Technology and National Research Council of Canada.

2.1. Preparation of ASCs. Subcutaneous adipose tissue was obtained from the abdominal regions of inbred male Lewis rats. The excised adipose tissue was minced and digested with collagenase I ( $2 \mathrm{mg} / \mathrm{mL}$, Worthington Biochemical Corp., Lakewood, NJ, USA) at $37^{\circ} \mathrm{C}$ for $20-30 \mathrm{~min}$. The digested adipose tissue was filtered twice with a $100 \mu \mathrm{m}$ and then with a $25 \mu \mathrm{m}$ nylon membrane to eliminate the undigested fragments. The cellular suspension was centrifuged at $1000 \times \mathrm{g}$ for $10 \mathrm{~min}$. The cell pellets were resuspended at a density of $5 \times 10^{6}$ cells $/ \mathrm{mL}$ in Cell-Culture Medium (CCM) with Dulbecco's Modified Eagle's Medium/Ham's F-12 (DMEM/F12; HyClone Laboratories, Logan, UT) containing $15 \%$ fetal bovine serum (FBS; HyClone, Logan, UT) and cultivated for $24 \mathrm{~h}$ at $37^{\circ} \mathrm{C}$ in $5 \% \mathrm{CO}_{2}$.

The ASCs were incubated for 2 days in a CCM containing $50 \mu \mathrm{g} / \mathrm{mL}$ SPIO nanoparticles (Feridex; Bayer Healthcare Pharmaceuticals, Berlin, Germany; $100 \mathrm{mg} / \mathrm{mL}, 62 \mathrm{~nm}$ in diameter) and $6 \mu \mathrm{g} / \mathrm{mL}$ protamine sulfate (a transfecting agent). Loading of SPIOs into ASCs was confirmed by Prussian blue staining.

2.2. Exposure of ASCs to the SMF. A $15 \mathrm{~mm}$ diameter (wide) and $1 \mathrm{~mm}$ thick neodymium-iron-boron (NdFeB) N50 grade disc or cubic magnet with the residual induction $(\mathrm{Br})$ of $600 \mathrm{mT}$ (Indigo Instruments, Waterloo, ON, Canada) was used to create the SMF. Circular magnets were inserted into each well of the first two adjacent columns on the 24- or 96-well plates (Figure 1(a)). ASCs and SPIOASCs were seeded into the wells of the first and last two columns, respectively. The magnet-embedded plates were firmly placed below the cell-cultured ones in a well-to-well manner in order to expose the first two columns to SMF (Figure 1(b)). Moreover, cubic magnets ( $1 \mathrm{~mm}$ thick, $15 \mathrm{~mm}$ wide, $\mathrm{Br}=$ $600 \mathrm{mT}$, Indigo Instruments, Waterloo, ON, Canada) were positioned under a Petri dish (Figure 1(c)). The exposed and the control ASCs were kept in the same incubator but with at least $30 \mathrm{~cm}$ distance gap. There was no detectable field from the magnet around the control ASCs. The distance between the single layer of ASCs and the surface of the magnet was constant and identical. The SMF induction values at inner wall of well and flask were $0.506 \pm 0.01$ Tesla by a LakeShore Model 420 Gaussmeter (LakeShore Cryotronics, Westerville, $\mathrm{OH}, \mathrm{USA}$ ) in incubators at $37^{\circ} \mathrm{C}$ in $5 \% \mathrm{CO}_{2}$ humidified atmosphere during the experiments. Magnetic induction values of the environmental geomagnetic field were about 5 orders of magnitude lower than those inside cell containers. All experiments were conducted in the conditions without heat generation.

The cells were cultured for a seven-day period with or without the continuous exposure of SMF. Following sevenday cultivation an aliquot of exposed and control cells were prepared for postexposure evaluation and induction differentiation. The 24-well plates were used for the proliferation rate measurement with an automated cell counter. The 96-well plates were used for cell viability and bromodeoxyuridine (BrdU) cell proliferation assays. The Petri culture dish was used for comet assay, apoptotic staining, flow cytometric assay, reverse transcription- (RT-) PCR, and induction differentiation analysis.

2.3. Cell Viability Assessment. ASC's viability was measured by the MTT [3-(4,5-methylthiazol-2-yl)-2,5-diphenyltetrazolium bromide] assay (Sigma-Aldrich, St. Louis, MO, 


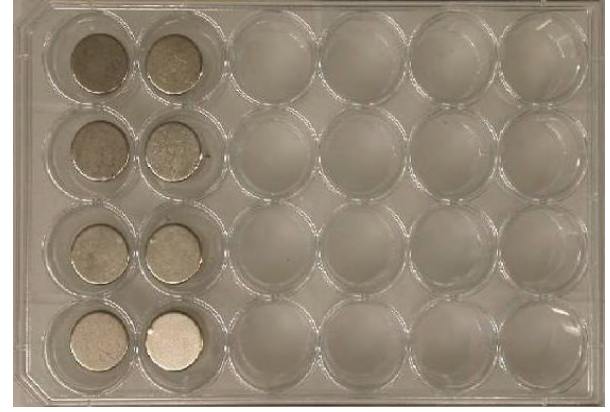

(a)

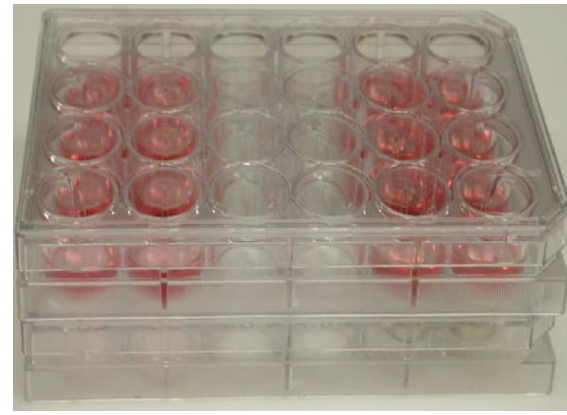

(b)

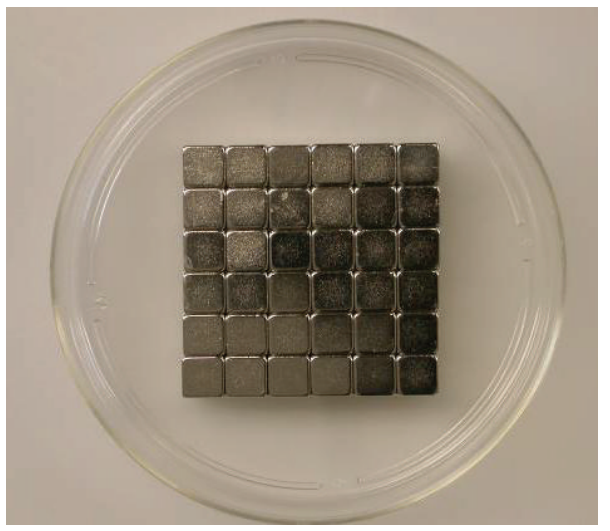

(c)

FIGURE 1: 0.5 T SMF exposure system. (a) Eight circular magnets were embedded in the wells of the first and second columns on the 24- or 96-well plates. (b) The magnet-embedded plates were placed firmly at the bottom of the cell-cultured ones in a well-to-well fashion. (c) Cubic magnets were positioned below a Petri dish.

USA). Briefly, a $5 \mathrm{mg} / \mathrm{mL}$ MTT salt solution was added to cells to give a final concentration of $2.5 \mathrm{mg} / \mathrm{mL}$ MTT. Cells were then incubated at $37^{\circ} \mathrm{C}$ for $1 \mathrm{~h}$. The final formazan product was dissolved in dimethyl sulfoxide and light absorbance was measured at $570 \mathrm{~nm}$. The amount of formazan was directly proportional to the number of live cells.

\subsection{Cell Proliferation Assay. For Cell Counting Kit (CCK)} assay, a Cell Counting Kit reagent (Sigma-Aldrich, St. Louis, MO, USA) was added to the well and incubated for $2 \mathrm{~h}$. Absorbance value was measured at $450 \mathrm{~nm}$ using a microplate reader (Bio-Rad Laboratories, Hercules, CA, USA). For BrdU incorporation, BrdU labeling reagent (Roche Diagnostics, Indianapolis, IN, USA) was added to each well and cells were reincubated for $24 \mathrm{~h}$ at $37^{\circ} \mathrm{C}$. After removing CCM, cells were fixed and DNA denatured by adding $200 \mathrm{~mL}$ of FixDenat (Roche Diagnostics, Indianapolis, IN, USA) for $30 \mathrm{~min}$ at room temperature. After removing FixDenat, antiBrdU-POD working solution was added to each well and left at room temperature on a shaker for $90 \mathrm{~min}$. Each well's absorbance was measured at $370 \mathrm{~nm}$ with a microplate reader (Bio-Rad Laboratories, Hercules, CA, USA).

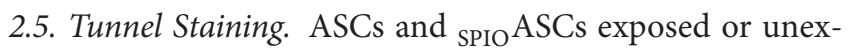
posed to SMF were stained by Terminal Deoxynucleotidyl Transferase Mediated dUTP Nick End Labeling (TUNEL) with In Situ Cell Death Detection Kit (Roche Diagnostics, Indianapolis, IN, USA) according to the manufacturer's instructions. After TUNEL, the sections were counterstained for nuclei with 4',6-diamidino-2-phenylindole (DAPI; Sigma-Aldrich, St. Louis, MO, USA). The TUNEL or DAPI positive nuclei were counted in three random fields under a Zeiss Axiophot fluorescence microscope (Carl Zeiss, Oberkochen, Germany).

2.6. Single Cell Gel Electrophoresis (Comet Assay). Five microliters of cells was mixed with $75 \mu \mathrm{L}$ low melting point agarose $\left(0.5 \%\right.$ at $\left.37^{\circ} \mathrm{C}\right)$ and pipetted onto slides precoated with $1 \%$ normal melting point agarose in 2 parallels. This suspension was maintained at $4^{\circ} \mathrm{C}$ until solidification of the agarose. The slides were immersed in freshly prepared cold cell lyses buffer for $24 \mathrm{~h}$ at $4^{\circ} \mathrm{C}$ and then placed in a horizontal electrophoresis unit (Bio-Rad Laboratories, Hercules, CA, USA) containing freshly prepared electrophoresis buffer. The electrophoresis was performed at $25 \mathrm{~V}, 300 \mathrm{~mA}$ for $30 \mathrm{~min}$. The DNA was stained with $50 \mu \mathrm{L}$ of $0.5 \mathrm{mg} / \mathrm{mL}$ ethidium bromide. Using a fluorescence microscope with wavelengths of 535 and $590 \mathrm{~nm}$, photography of a representative image of each slide was taken.

2.7. Flow Cytometry Analysis. The cells were fixed for $10 \mathrm{~min}$ in $1 \%$ paraformaldehyde. After washing twice with PBS, cells were incubated with primary antibodies at room temperature 
for $30 \mathrm{~min}$. The antibodies used were as follows: fluorescein isothiocyanate- (FITC-) conjugated anti-rat CD49d, CD54, and CD73 (Invitrogen, Carlsbad, CA, USA). Flow cytometric analysis was performed on a fluorescence-activated cell sorter (BD Biosciences, CA, USA).

2.8. Adipogenic and Osteogenic Differentiation. Before performing the experiments, ASCs and ${ }_{\text {SPIO ASCs were cultured }}$ for seven days with or without SMF exposure. Adipogenic differentiation was induced by incubation of the cells for 12 days in DMEM containing 5\% FBS, $10 \mu \mathrm{M}$ bovine insulin, 250 isobutyl-methylxanthine, $200 \mu \mathrm{M}$ indomethacin, $1 \mu \mathrm{M}$ dexamethasone, $5 \mu \mathrm{g} / \mathrm{mL}$ streptomycin, and $5 \mathrm{U} / \mathrm{mL}$ penicillin. Osteogenic induction was carried out by cultivating the ASCs for 28 days in DMEM containing 10\% FBS, $10 \mathrm{mM}$ $\beta$-glycerophosphate, $50 \mu \mathrm{M}$ ascorbate-2-phosphate, $10 \mathrm{nM}$ $1,25(\mathrm{OH})_{2}$ vitamin $\mathrm{D} 3,5 \mu \mathrm{g} / \mathrm{mL}$ streptomycin, and $5 \mathrm{U} / \mathrm{mL}$ penicillin.

2.9. Oil-Red-O Staining. After 12-day adipogenic induction, the cells were fixed in $4 \%$ paraformaldehyde for $30 \mathrm{~min}$ at room temperature and washed twice with distilled water. Then they were stained in Oil-red-O at a ratio of $60 \%$ stock solution ( $0.5 \%$ weight/volume in isopropanol) to $40 \%$ distilled water for $15 \mathrm{~min}$. The cells were examined under light microscopy (TE2000-U; Nikon, Tokyo, Japan). Oil-redO levels in the stained cells were determined by measuring the optical density (OD) with a spectrophotometer (NanoDrop Technologies, Wilmington, DE, USA) at $495 \mathrm{~nm}\left(\mathrm{OD}_{450}\right)$.

2.10. Alkaline Phosphatase Staining. After 28-day osteogenic induction, the cells were fixed in $4 \%$ paraformaldehyde for $30 \mathrm{~min}$ at room temperature and washed twice with distilled water. Then they were stained in $1 \mathrm{~mL}$ Michaelis buffer containing $10 \mathrm{mg}$ nitroblue tetrazolium chloride/bromo4-chloro-3-indolyl phosphate toluidine salt (NBT/BCIP) for $20 \mathrm{~min}$ at $37^{\circ} \mathrm{C}$. The NBT/BCIP undergoes an oxidation/reduction reaction after dephosphorylation by alkaline phosphatase (ALP), giving rise to an insoluble brown product. The stained cells were then examined under a light microscope. The brown product was also quantified with a spectrophotometer at $465 \mathrm{~nm}$.

2.11. RT-PCR. Total RNA from the ASCs was extracted using the TRIzol Reagent (Invitrogen, Carlsbad, CA, USA) protocol. One microgram of RNA was reversely transcribed using SuperScript III reverse transcriptase (Invitrogen, Carlsbad, CA, USA). cDNA was used as a template for PCR amplification. Glyceraldehyde-3-phosphate dehydrogenase (GAPDH) was used as an internal control. The genes for adipogenic differentiation were Lipoprotein Lipase (LPL) and Peroxisome Proliferator-Activated Receptor Gamma (PPAR$\gamma$ ). The genes for osteogenic differentiation were the Secreted Phosphor-protein 1 (SPP1) and Osterix (OSX).

Expressions of cytokines Vascular Endothelial Growth Factor (VEGF), Transforming Growth Factor Beta 1 (TGF$\beta 1$ ), Insulin-like Growth Factor-1 (IGF-1), and stem cellspecific marker Octamer-4 (Oct-4), Stem Cell Antigen-1
(Scal), and ATP-binding Cassette Subfamily B Member 1 (ABCB1) were also determined. Sequences for all the primers used in this study are detailed in Table 1.

2.12. Statistical Analysis. All data are expressed as means \pm standard deviation. Statistical significance was evaluated with unpaired Student's $t$-test for comparisons between two means, with ANOVA for more than two means. Data were considered significant when the $P$ value was $<0.05$. All statistical analyses were performed with SPSS version 12.0 software (SPSS, Inc., Chicago, IL, USA).

\section{Results}

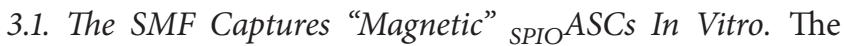
ASCs appeared as fibroblast-like morphology under a phasecontrol microscopy. The Prussian blue staining of the ASCs showed intracytoplasmic iron inclusions as dense bluestained vesicles, and the magnetic SPIOs were distributed evenly around the nucleus of the ASCs as spherical shell (Figure 2(a)).

The ${ }_{\text {SPIO }}$ ASCs were resuspended at the cell-culture dish, and then the magnet was placed behind the outer wall. After seven days of culture, a distinct cell population was focally formed on the inner dish wall. Conversely, the smaller cell population was present at place one centimeter away from the magnet (Figure 2(b)).

3.2. The SMF Decreases the Viability and Proliferation of ASCs and ${ }_{S P I O} A S C s$. Cell viability and proliferation rate have been normalized to values measured from the control ASCs, defined as $100 \%$. Cell viability rates were $100 \%, 102 \% \pm 4 \%$, $92 \% \pm 2 \%$, and $93 \% \pm 2 \%$ in ASCs, ${ }_{\text {SPIO }}$ ASCs, ASCs-SMF, and SPIOASCs-SMF, respectively (Figure 3(a)). Cell proliferation percentages measured by cell counting were $100 \%, 104 \% \pm 5 \%$, $93 \% \pm 3 \%$, and $92 \% \pm 3 \%$ in ASCs, sPIO ASCs, ASCs-SMF, and ${ }_{\text {SPIO }}$ ASCs-SMF, respectively (Figure 3(b)). Similarly, cell proliferation rates assessed by BrdU ELISA were $100 \%$, $101 \% \pm 4 \%, 89 \% \pm 3 \%$, and $91 \% \pm 3 \%$ in ASCs, sPIO ASCs, ASCs-

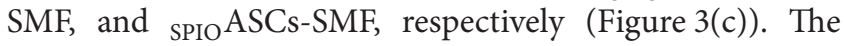
SMF-treated cells exhibited statistically significant decline in viability and proliferation in comparison with the control cells unexposed to SMF after seven-day exposure.

3.3. The SMF Inhibits the Expression of Surface Antigens in ASCs and ${ }_{S P I O} A S C s$. The percentage of cells expressing CD49d, CD54, and CD73 after seven days of culture was reduced in ASCs-SMF and ${ }_{\text {SPIO }}$ ASCs-SMF compared to ASCs and ${ }_{\text {SPIO }}$ ASCs $(76.35 \% \pm 3.81 \%$ and $75.91 \% \pm 5.05 \%$ versus $84.21 \% \pm 4.21 \%$ and $88.47 \% \pm 4.42 \%$ for CD $49 \mathrm{~d} ; 89.57 \% \pm$ $3.27 \%$ and $88.19 \% \pm 4.15 \%$ versus $98.55 \% \pm 4.27 \%$ and $98.50 \% \pm 3.92 \%$ for CD $54 ; 85.86 \% \pm 4.81 \%$ and $86.27 \% \pm 4.96 \%$ versus $96.92 \% \pm 3.04 \%$ and $96.36 \% \pm 3.12 \%$ for CD73, resp.) (Figure 4(a)).

3.4. The SMF Does Not Cause the DNA Damage and Apoptosis of ASCs and ${ }_{S P I O} A S C s$. The presence of comet tail was indicative of DNA double-strand breaks. Seven-day exposure 
TABLE 1: Primers of specific markers for transdifferentiation, cytokines, and stem cell genetic markers.

\begin{tabular}{|c|c|c|c|}
\hline Gene & Primer sequence & Fragment, bp & GenBank number \\
\hline \multicolumn{4}{|l|}{ LPL } \\
\hline Forward & 5'CACCTACACACAAGCAAAGCCCCA3' & \multirow{2}{*}{459} & \multirow{2}{*}{ NM_012598 } \\
\hline Reverse & 5'GTGCTGTTCATCAGAGTGAGTTGGC3' & & \\
\hline \multicolumn{4}{|l|}{ PPAR- $\gamma$} \\
\hline Forward & 5'CTACACCATGCTGGCCTCCCTGATG3' & \multirow{2}{*}{481} & \multirow{2}{*}{ NM_013124 } \\
\hline Reverse & $5^{\prime}$ TTGTCAGCGACTGGGACTTTTCTGC3' & & \\
\hline \multicolumn{4}{|l|}{ SPP1 } \\
\hline Forward & 5'CGACAGTCAG GCGAGTTCCA AAGCC 3' & \multirow{2}{*}{470} & \multirow{2}{*}{ NM_012881 } \\
\hline Reverse & 5'GCTGTTCCTG TAAGTTTGCC TGCCTC $3^{\prime}$ & & \\
\hline \multicolumn{4}{|l|}{ OSX } \\
\hline Forward & $5^{\prime}$ AGTGGTGCAGGCAAACCTCCCCGGG $3^{\prime}$ & \multirow{2}{*}{405} & \multirow{2}{*}{ BK00141 } \\
\hline Reverse & $5^{\prime}$ GACCTGGCTCCCCGTGGGTGCGCTG $3^{\prime}$ & & \\
\hline \multicolumn{4}{|l|}{ VEGF } \\
\hline Forward & 5'AGGTA CAGAG CAATG GGGCA GG $3^{\prime}$ & \multirow{2}{*}{689} & \multirow{2}{*}{ NM_03836 } \\
\hline Reverse & $5^{\prime}$ ACGGA ATATC TCGGA AAACT GCTC $3^{\prime}$ & & \\
\hline \multicolumn{4}{|l|}{ IGF-1 } \\
\hline Forward & 5'CATGT CGTCT TCACA TCTCT TCTAC $3^{\prime}$ & \multirow{2}{*}{299} & \multirow{2}{*}{ NM_001082477 } \\
\hline Reverse & $5^{\prime}$ CTTGT GTGTC GATAG GGGCT GGGAC $3^{\prime}$ & & \\
\hline \multicolumn{4}{|l|}{ TGF- $\beta 1$} \\
\hline Forward & 5'AAGGCTCGCCAGTCCCCCGA3' & \multirow{2}{*}{400} & \multirow{2}{*}{ NM_021578.2 } \\
\hline Reverse & 5'AGTGGGGGTCAGCAGCCGGT3' & & \\
\hline \multicolumn{4}{|l|}{ OCT4 } \\
\hline Forward & $5^{\prime}$ ACCATCTGCCGCTTCGAGGC $3^{\prime}$ & \multirow{2}{*}{526} & \multirow{2}{*}{ NM_001009178 } \\
\hline Reverse & $5^{\prime}$ TGGCTCACCTCATCCCCAGG 3' & & \\
\hline \multicolumn{4}{|l|}{ Scal } \\
\hline Forward & $5^{\prime}$ CCCGTGGACCCTGCCAGTGC $3^{\prime}$ & \multirow{2}{*}{761} & \multirow{2}{*}{ X91619 } \\
\hline Reverse & $5^{\prime}$ TGGCACCTGCGCACCССТTC $3^{\prime}$ & & \\
\hline \multicolumn{4}{|l|}{$\mathrm{ABCB} 1$} \\
\hline Forward & $5^{\prime}$ GCCATGGCAGTGGGGCAGGT $3^{\prime}$ & \multirow{2}{*}{600} & \multirow{2}{*}{ NM_133401 } \\
\hline Reverse & $5^{\prime}$ GATGCGCTGCTTCTGCCCGC $3^{\prime}$ & & \\
\hline GAPDH & & & \\
\hline Forward & $5^{\prime}$ ATCTGACATGCCGCCTGGAGAAACC $3^{\prime}$ & 287 & NM 017008 \\
\hline Reverse & $5^{\prime}$ CAGGGTTTCTTACTCCTTGGAGGCC $3^{\prime}$ & 207 & 1 VIVI-U17 \\
\hline
\end{tabular}

to $0.5 \mathrm{~T}$ SMF was not associated with the DNA damage with comet tail in four cell groups (Figure 4(b)). The percentages of cell with integral DNA structure were not significantly different among the ASCs $(98.49 \% \pm 0.44 \%)$, sPIO ASCs $(98.49 \% \pm$ $0.62 \%)$, ASCs-SMF $(98.51 \% \pm 0.58 \%)$, and ${ }_{\text {SPIO ASCs-SMF }}$ $(98.36 \% \pm 0.35 \%$ ) (Figure $4(\mathrm{c})$ ). Seven-day exposure to a $0.5 \mathrm{~T}$ SMF did not result in the apoptosis of ASCs and ${ }_{\text {SPIO ASCs }}$ (data not shown).

3.5. The SMF Depresses Cytokines Secretion and Stem Cell Marker Expression in ASCs and ${ }_{S P I O} A S C s$. Figure 5(a) showed the representative results of RT-PCR for angiogenic cytokines including IGF-1, VEGF, and TGF- $\beta 1$. PCR product band intensities, relative to GAPDH, have been normalized to values measured from the control ASCs, defined as $100 \%$.
ASCs-SMF and ${ }_{\text {SPIO }}$ ASCs-SMF expressed the lower levels of IGF-1 (0.87- and 0.84-fold lower, resp.), VEGF (0.80- and 0.77 -fold lower, resp.), and TGF- $\beta 1$ (0.88- and 0.86-fold lower,

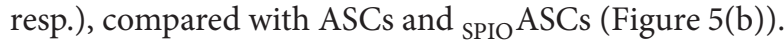

Figure 5(c) showed the representative results of RT-PCR for stem cell markers Scal, ABCB1, and Oct-4. ASCs-SMF and ${ }_{\text {SPIO }}$ ASCs-SMF expressed the lower levels of Scal (0.78and 0.83 -fold lower, resp.), ABCB1 (0.87- and 0.89-fold lower, resp.), and Oct-4 (0.90- and 0.91-fold lower, resp.), compared with ASCs and ${ }_{\text {SPIO }}$ ASCs (Figure 5(d)).

3.6. The SMF Inhibits the Adipogenic Differentiation of ASCs and ${ }_{S P I O} A S C s$. Histological staining showed strong Oil-redO staining of the cytoplasmic lipid droplet (Figure 6(a)). Oil-red-O OD values were normalized to the level from 

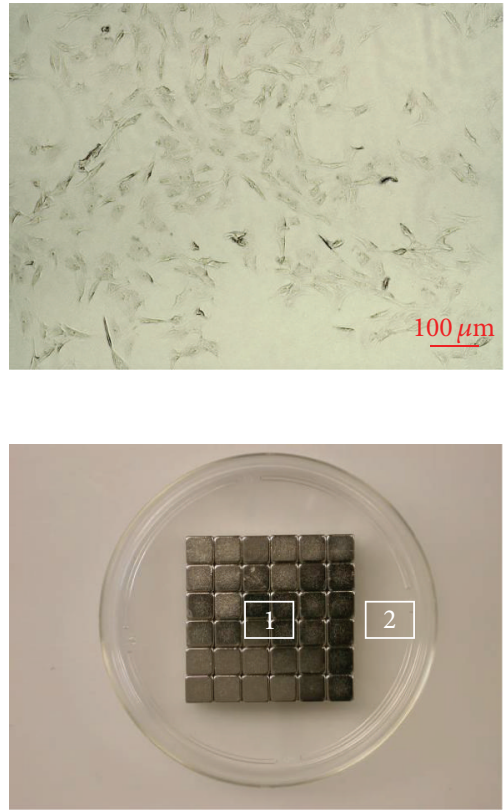

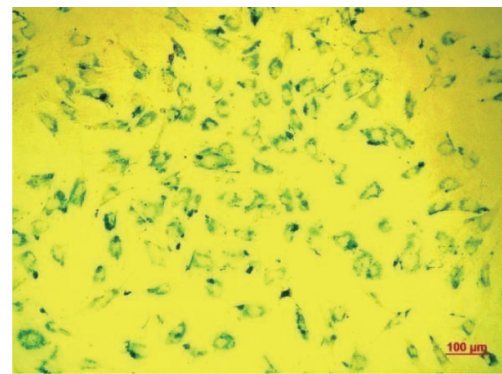

(a)

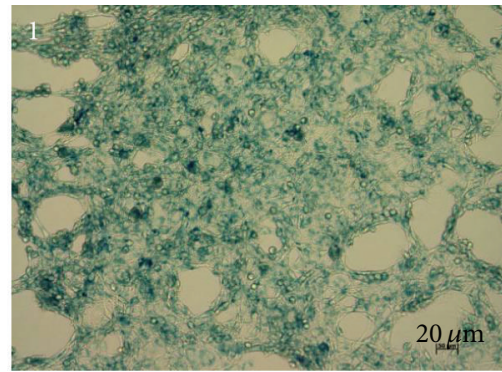

(b)
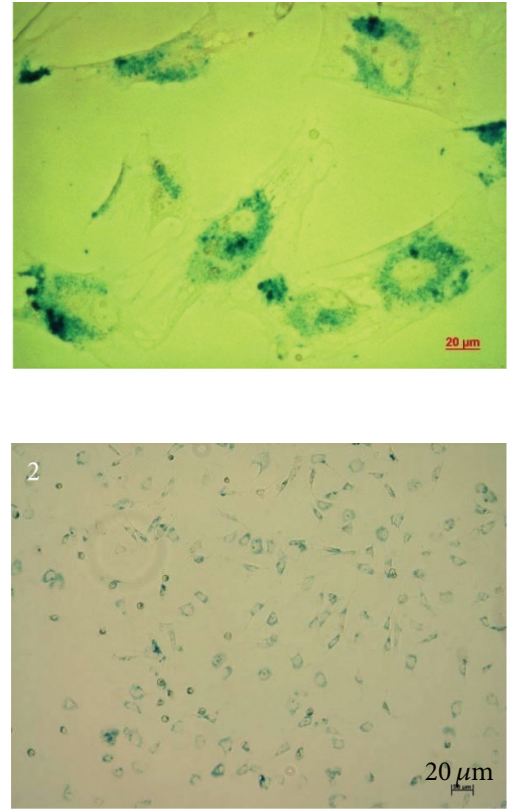

$0 \mu \mathrm{m}$

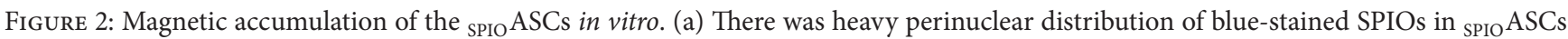

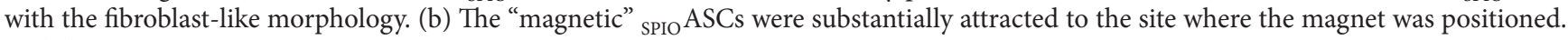
Scale bar represents $20 \mu \mathrm{m}, 50 \mu \mathrm{m}$, or $100 \mu \mathrm{m}$.

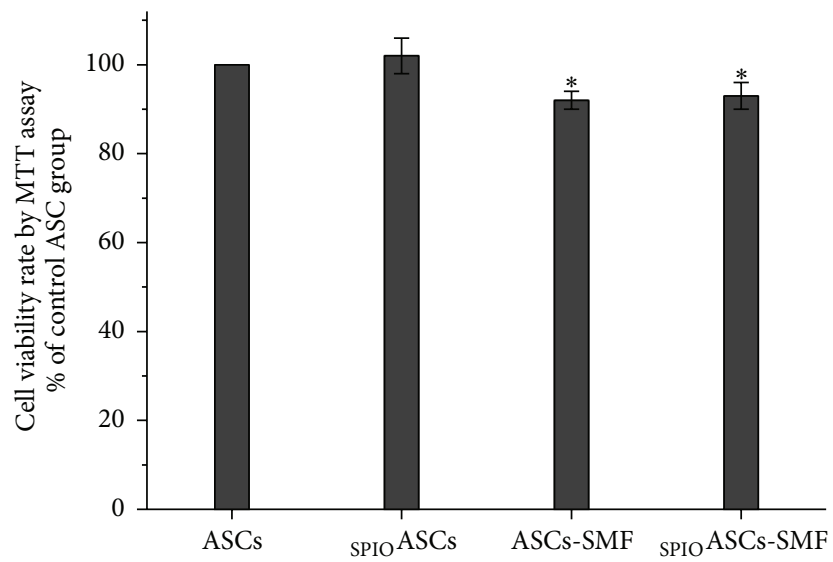

(a)

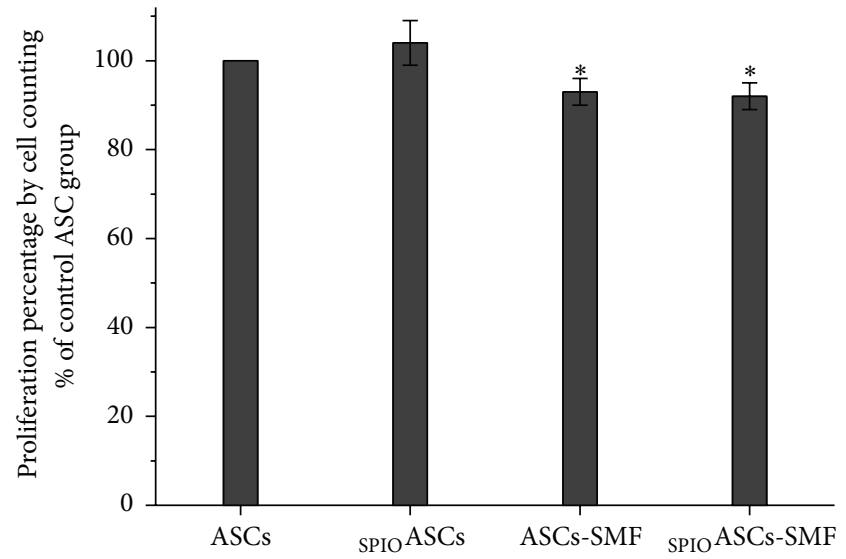

(b)

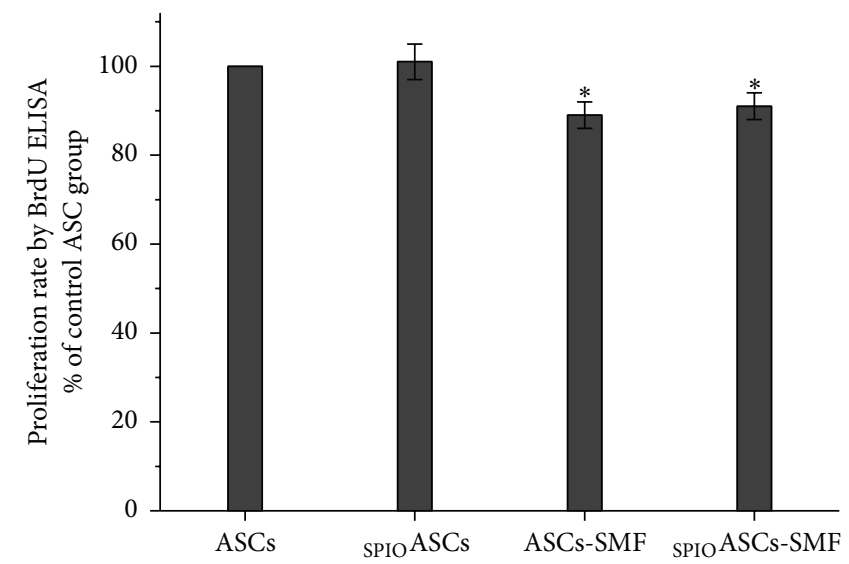

(c)

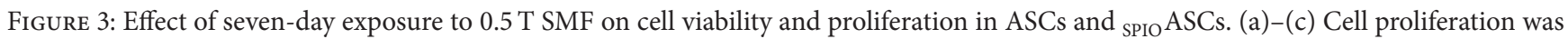
assessed by cell counting (b) and BrdU assay (c). The cell viability (a) and proliferation rate ((b)-(c)) were significantly lower in the ASCs-SMF and ${ }_{\text {SPIO }}$ ASCs-SMF than in ASCs and ${ }_{\text {SPIO }}$ ASCs. ${ }^{*} P<0.05$ versus ASCs or ${ }_{\text {SPIO }}$ ASCs. 


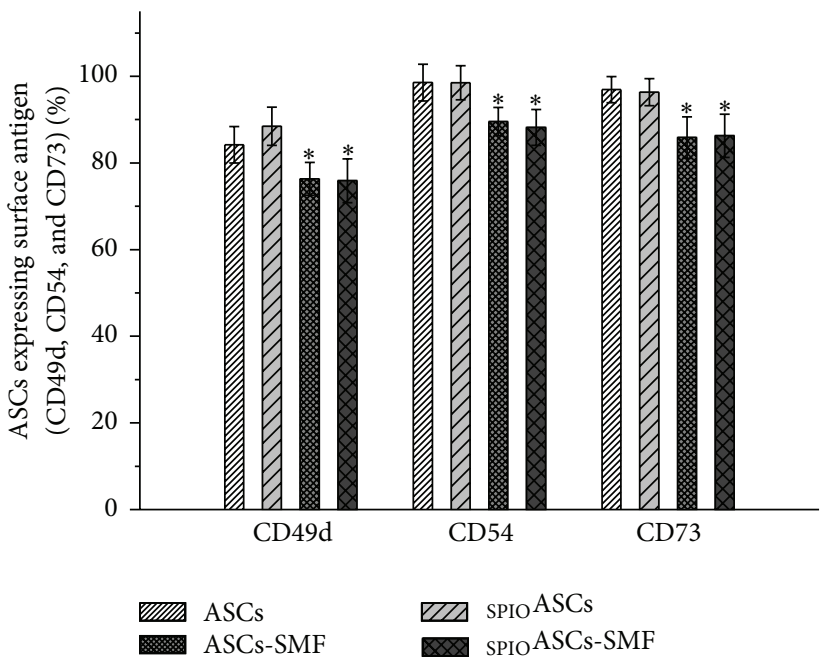

(a)
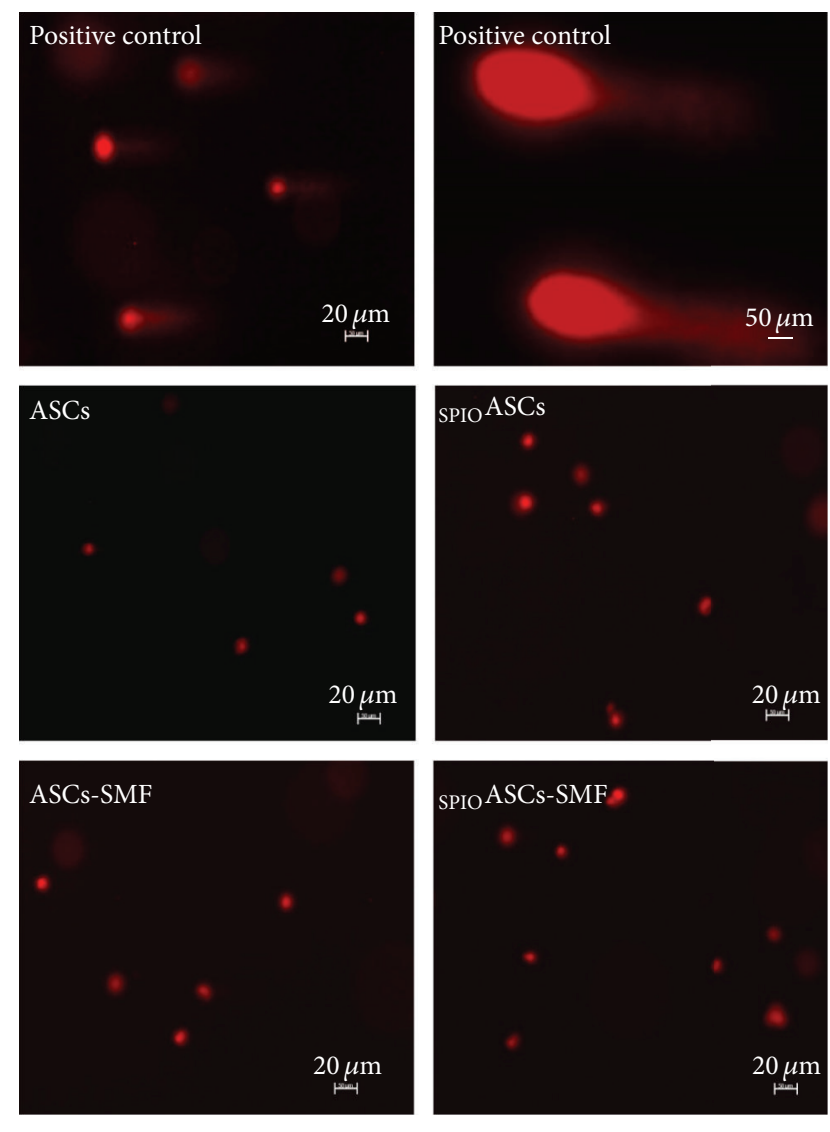

(b)

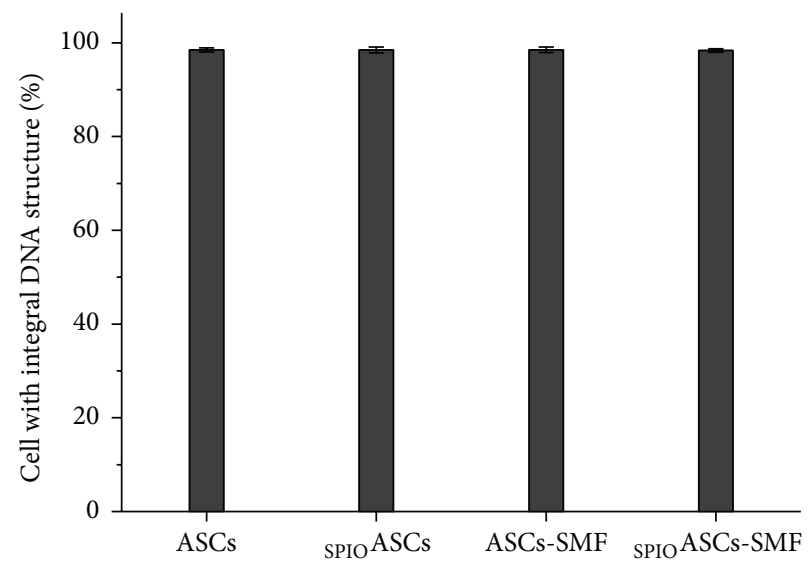

(c)

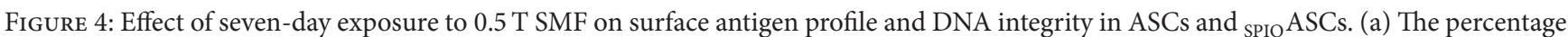

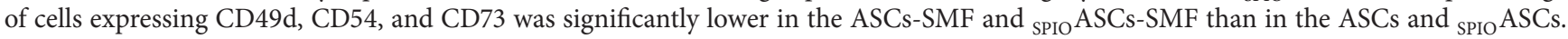
(b) Representative comet assay result. DNA damage with comet tail was not observed at four groups of ASCs. (c) The percentages of cell with integral DNA structure did not differ among ASCs, SPIO ASCs, ASCs-SMF, and ${ }_{\text {SPIO }}$ ASCs-SMF. Scale bar represents $20 \mu \mathrm{m}$ or $50 \mu \mathrm{m}$. ${ }^{*} \mathrm{P}<0.05$ versus ASCs or ${ }_{\text {SPIO }}$ ASCs. 


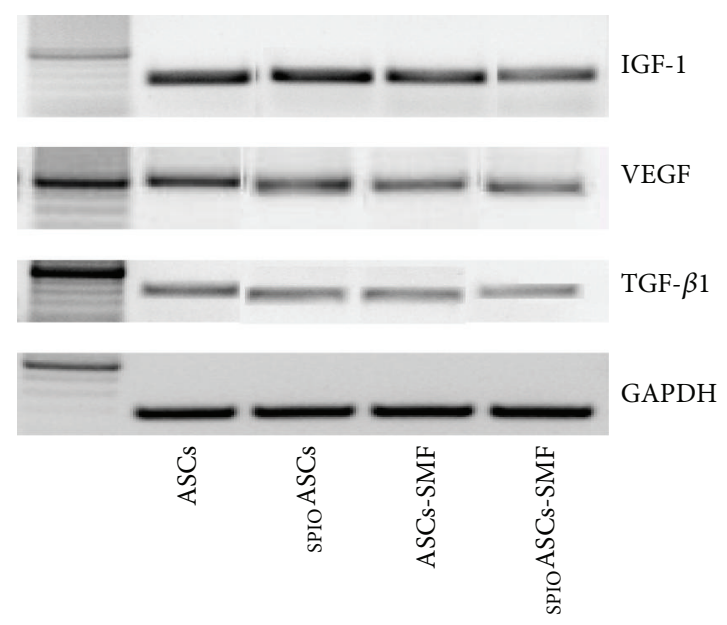

(a)

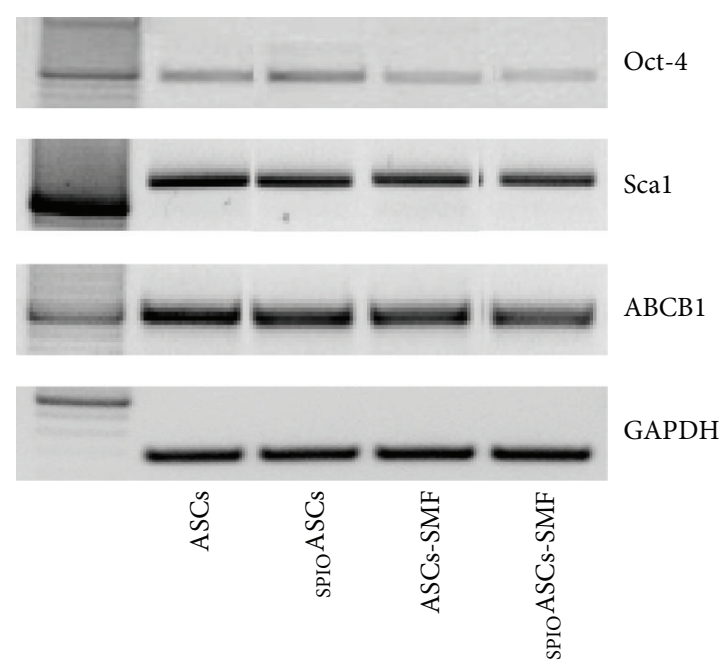

(c)

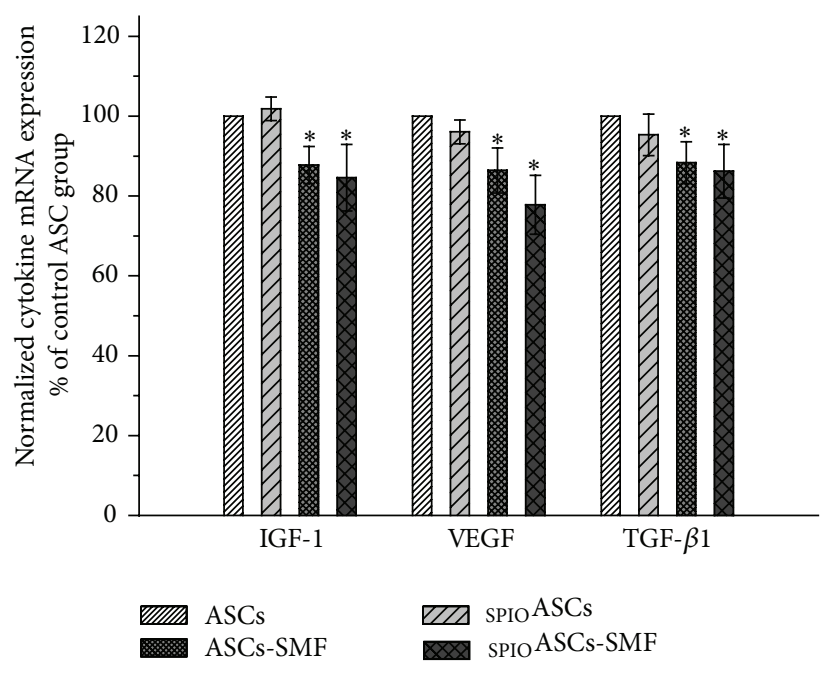

(b)

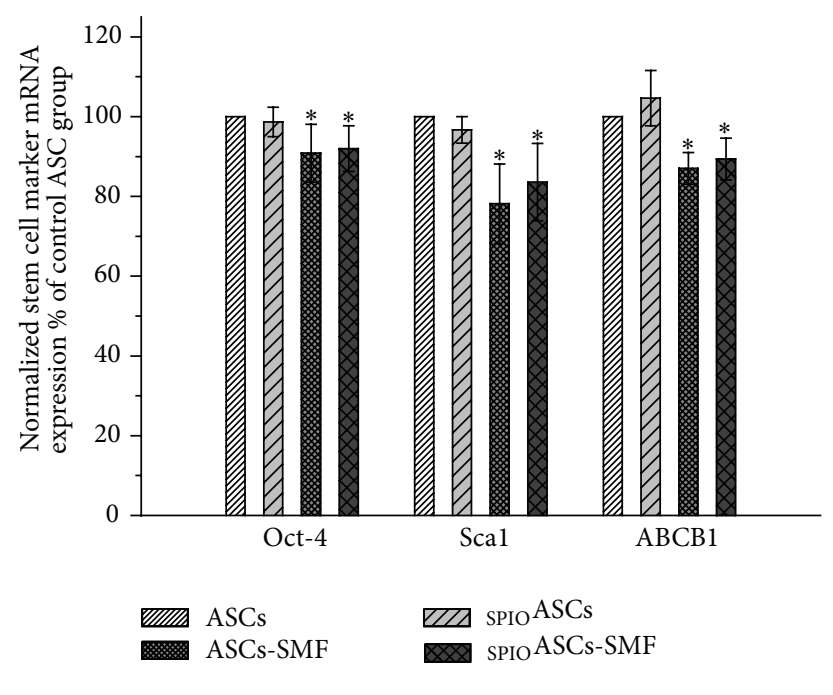

(d)

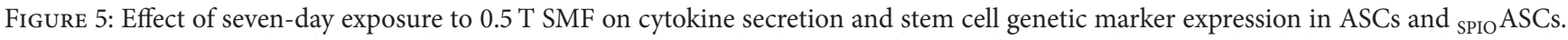
(a) Representative results of RT-PCR for IGF-1, VEGF, and TGF- $\beta 1$. (b) Quantification after normalization to levels from control ASCs. The

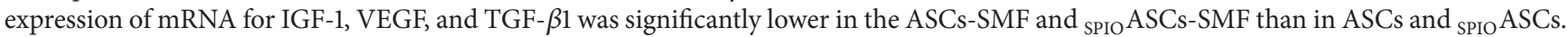
(c) Representative results of RT-PCR for Scal, ABCB1, and Oct-4. (d) Quantification after normalization to levels from control ASCs. The

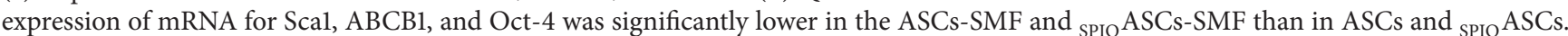
${ }^{*} P<0.05$ versus ASCs or ${ }_{\text {SPIO }}$ ASCs.

the control ASCs defined as 100\%. ASCs-SMF and ${ }_{\text {SPIO }}$ ASCsSMF had lower Oil-red-O OD value (0.89-fold and 0.89fold lower, resp.) compared with ASCs and ${ }_{\text {SPIO ASCs }}$ (Figure 6(b)).

Figure 6(c) showed the representative results of RT-PCR for adipogenic-related genes LPL and PPAR- $\gamma$. PCR product band intensities, relative to GAPDH, have been normalized to values measured from the control ASCs, defined as $100 \%$. ASCs-SMF and ${ }_{\text {SPIO }}$ ASCs-SMF expressed slightly lower levels of LPL (0.91- and 0.90-fold lower, resp.) and PPAR- $\gamma$ (0.79- and 0.85-fold lower, resp.) compared with ASCs and SPIO ASCs (Figure 6(d)).
3.7. The SMF Inhibits the Osteogenic Differentiation of ASCs and ${ }_{S P I O} A S C s$. Histological staining showed strong ALP staining (Figure 7(a)). ALP OD values were normalized to the level from the control ASCs, defined as $100 \%$. ASCs-SMF and ${ }_{\text {SPIO }}$ ASCs-SMF had lower ALP OD value (0.90-fold and 0.88 -fold lower, resp.) compared with ASCs and ${ }_{\text {SPIO ASCs }}$ (Figure 7(b)).

Figure 7(c) showed the representative results of RT-PCR for osteogenic-related genes SPP and OSX. PCR product band intensities, relative to GAPDH, have been normalized to values measured from the control ASCs, defined as $100 \%$.

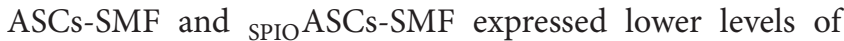




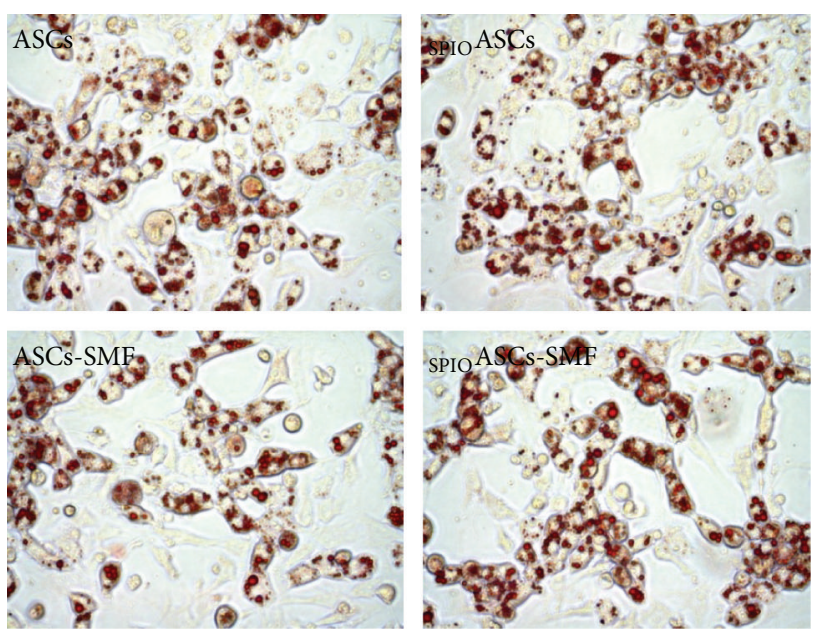

(a)

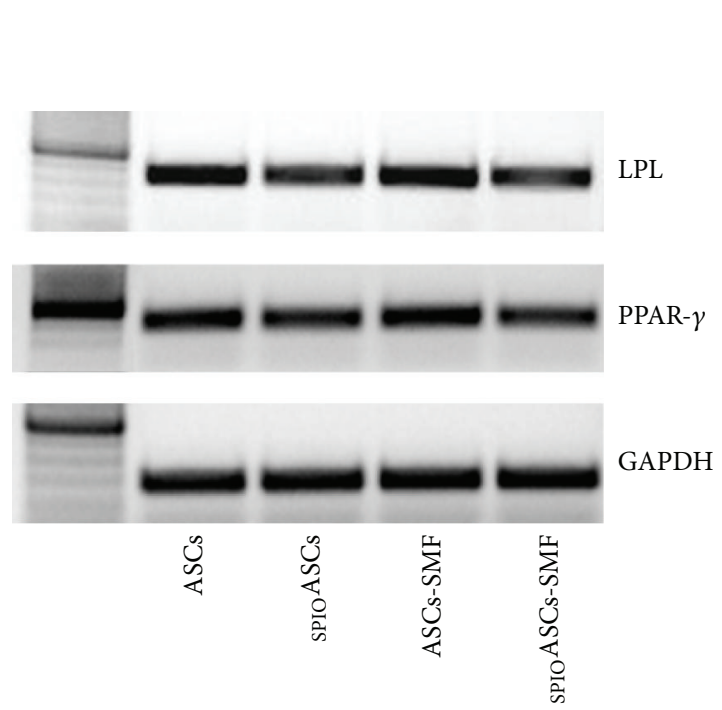

(c)

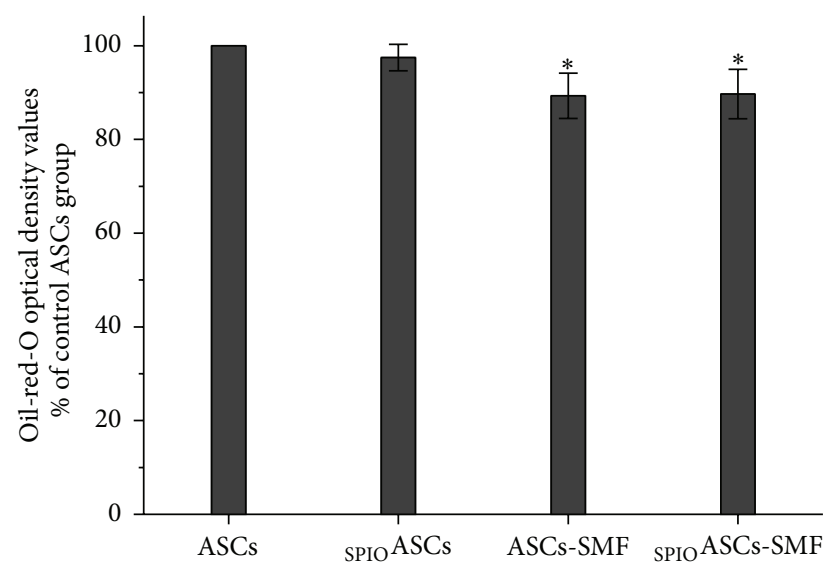

(b)

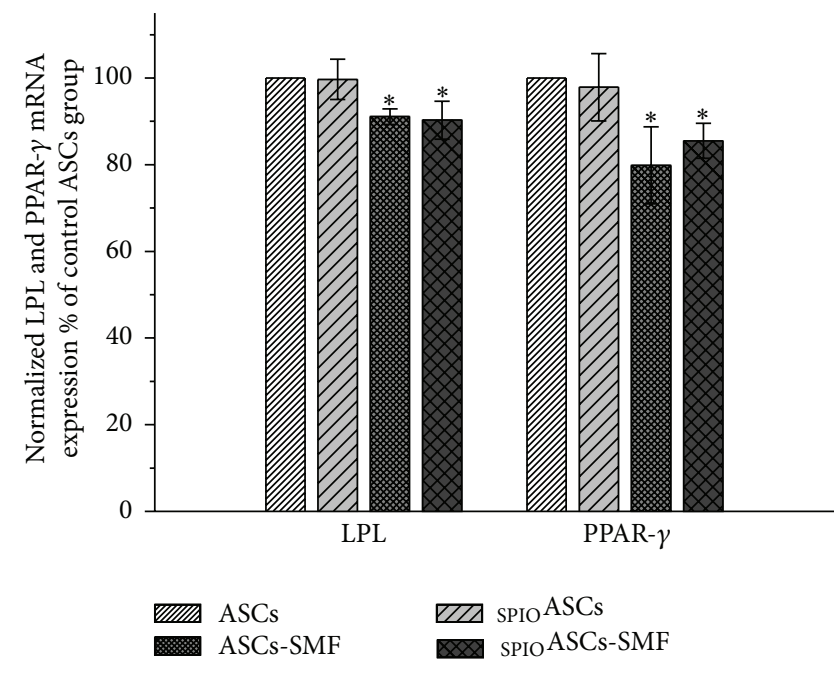

(d)

FIGURE 6: Effect of seven-day exposure to 0.5 T SMF on adipogenic differentiation in ASCs and SPIOASCs. (a) Representative results of histochemical staining for Oil-o-red. (b) Quantification after normalization to levels from control ASCs. The Oil-o-red optical density value

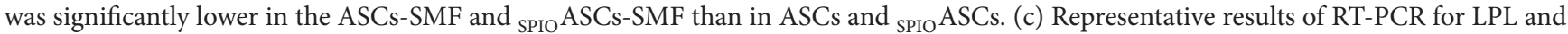
PPAR- $\gamma$. (d) Quantification after normalization to levels from control ASCs. The expression of mRNA for LPL and PPAR- $\gamma$ was significantly lower in the ASCs-SMF and ${ }_{\mathrm{SPIO}}$ ASCs-SMF than in ASCs and ${ }_{\mathrm{SPIO}}$ ASCs. Scale bar represents $100 \mu \mathrm{m} .{ }^{*} P<0.05$ versus ASCs or ${ }_{\text {SPIO }}$ ASCs.

OSX (0.87- and 0.86-fold lower, resp.) and SPP (0.91- and 0.88 -fold lower, resp.) compared with ASCs and ${ }_{\text {SPIO ASCs }}$ (Figure $7(\mathrm{~d})$ ).

\section{Discussion}

We have demonstrated that extended exposure to a $0.5 \mathrm{~T}$ SMF inhibits the cell viability and proliferation of ASCs with or without SPIO labeling. Our results are consistent with previous studies showing that SMF exposure decreases the cell proliferation. Marędziak et al. reported that seven-day exposure to a $0.5 \mathrm{~T}$ SMF significantly reduced the proliferation rate of ASCs of canine origin [18]. Javani Jouni et al. demonstrated that increasing of intensity $(>15 \mathrm{mT})$ and time of SMF exposure ( $>96$ hours) significantly decreased the viability percent and proliferation rate in BMSCs [19]. Rosen and Chastney found that a two-week exposure to a $0.5 \mathrm{~T}$ SMF was associated with a $37 \%$ decline in growth in GH3 cells with persistence for two weeks after the end of exposure [20]. When the exposure was extended to four weeks, the decline in growth was $51 \%$ with persistence for three weeks following removal from the magnet [20]. Raylman et al. reported that a $64 \mathrm{~h}$ exposure to a $7 \mathrm{~T}$ SMF reduced the viable cell number and inhibited the growth of three human tumor cell lines including HTB63 (melanoma), HTB 77 IP3 (ovarian carcinoma), and CCL 86 (lymphoma) [21]. There was no 

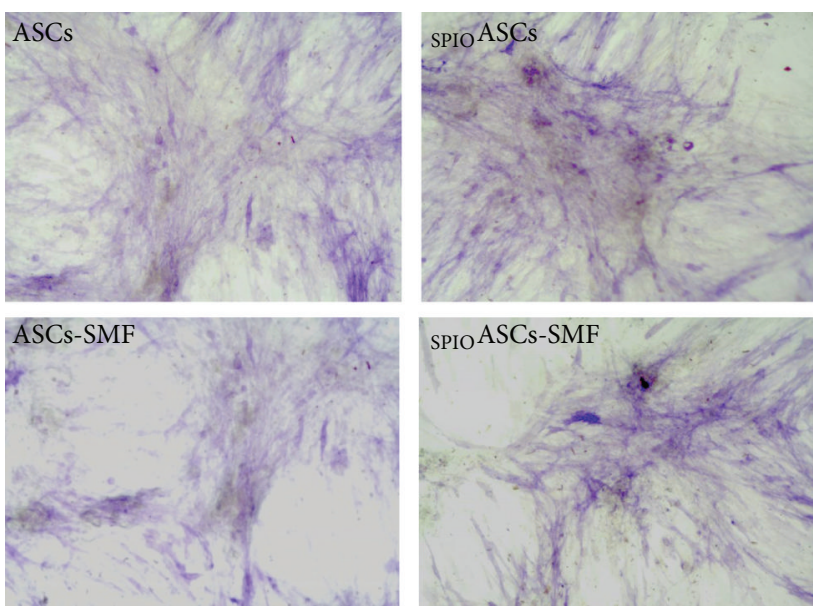

(a)

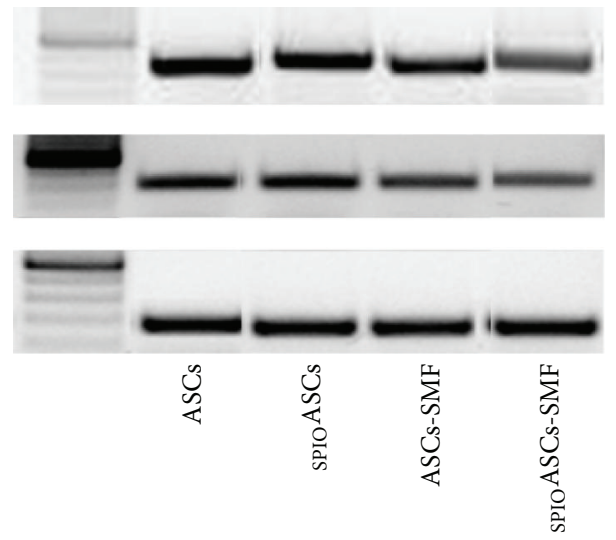

(c)

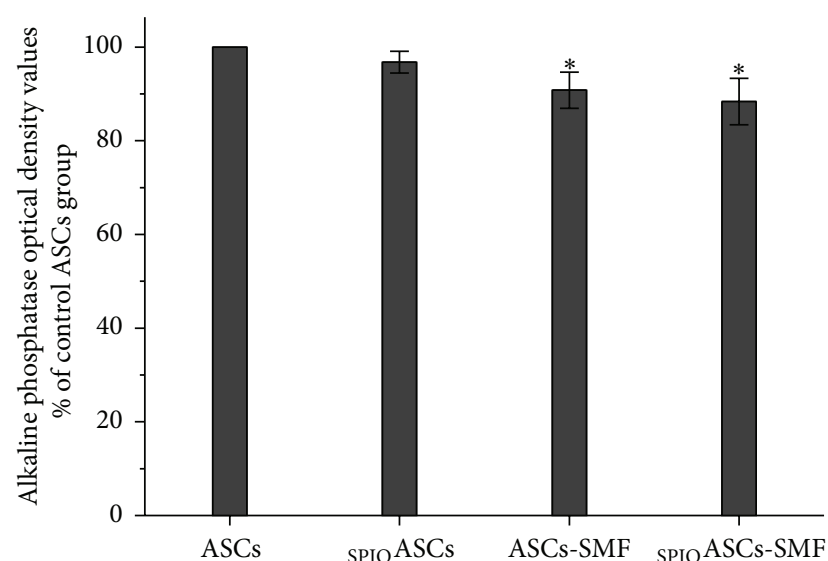

(b)
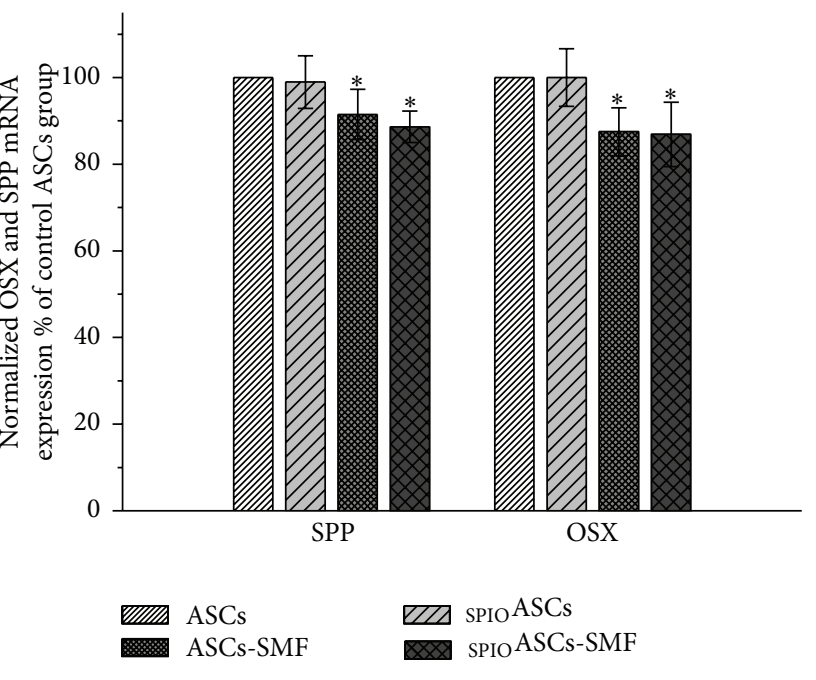

(d)

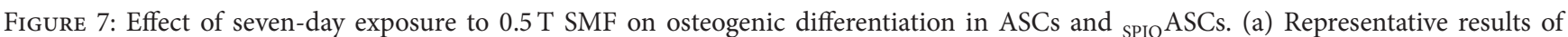
histochemical staining for alkaline phosphatase. (b) Quantification after normalization to levels from control ASCs. The alkaline phosphatase

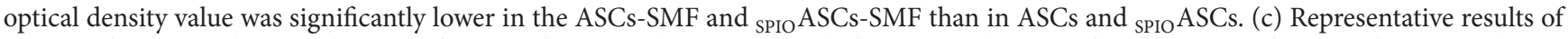
RT-PCR for SPP and OSX. (d) Quantification after normalization to levels from control ASCs. The expression of mRNA for SPP and OSX was significantly lower in the ASCs-SMF and ${ }_{\text {SPIO }}$ ASCs-SMF than in ASCs and ${ }_{\text {SPIO }}$ ASCs. Scale bar represents $100 \mu \mathrm{m} .{ }^{*} P<0.05$ versus ASCs or ${ }_{\text {SPIO }}$ ASCs.

evidence that altered cell cycle and DNA strand break should be responsible for the magnetically induced slowed growth rate [21].

We found that SMF exposure does not have a harmful

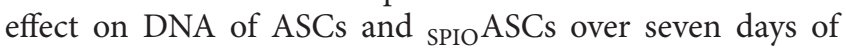
exposure. The result is fairly consistent with those previously published papers. Amara et al. showed that SMF exposure ( $250 \mathrm{mT}$, during $3 \mathrm{~h}$ ) did not cause DNA damage in THP1 cells [22]. Kubinyi et al. examined the effect of SMF on the DNA damage in leukocytes with exposures of homogeneous and inhomogeneous SMF for 1,4 , and $18 \mathrm{~h}$, and they also could not identify any change in the DNA damage [23]. Reddig et al. demonstrated that exposure of human peripheral blood mononuclear cells to $7 \mathrm{~T}$ SMF did not induce DNA doublestrand breaks [24].

In the study, the percentage of cells expressing surface antigen (CD49d, CD54, and CD73) was reduced in the ASCs and ${ }_{\text {SPIO }}$ ASCs exposed to the SMF compared with the control

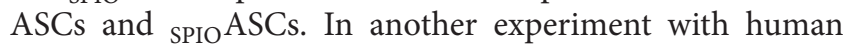
peripheral blood mononuclear cells, exposure for $2 \mathrm{~h}$ to a $0.5 \mathrm{~T}$ SMF resulted in a significantly reduced percentage of cells expressing CD69 after $24 \mathrm{~h}$ of in vivo culture [25]. Kim et al. reported that the expression levels of CD73, CD90, and CD105 were decreased in BMSCs exposed to a frequency of $45 \mathrm{~Hz}$ and an induction value of $1 \mathrm{mT}$ EMF twice every 8 hours per day for 7 days [26]. 
We also showed that exposure to a $0.5 \mathrm{~T}$ SMF up to seven days inhibited the release of angiogenic cytokines (VEGF, IGF-1, and TGF- $\beta 1$ ) and the expression of stem cell markers (Oct-4, Sal-1, and ABCB1) in ASCs and ${ }_{\text {SPIO }}$ ASCs. The present study is the first one to investigate whether the SMF exposure impacts the cytokine and stem cell marker expression of ASCs and sPIOASCs. Previously, Gruchlik et al. reported that SMF exposure (300 mT, $24 \mathrm{~h}$ ) inhibited the Interleukin(IL-) 6 secretion in normal human colon myofibroblasts [27]. Vergallo et al. demonstrated that exposure to a strong SMF (1.4 T) for up to 24 hours had a significant inhibitory effect on the release of proinflammatory cytokines IL-6, IL-8, and INF- $\alpha$ from macrophage [28]. Aldinucci et al. reported that exposure to a strong SMF (4.75 T) for 24-48 hours significantly decreased the production of IL-2 in human peripheral blood mononuclear cells [29].

In this study, moderate intensity SMF inhibited ASCs' adipogenic differentiation, which was shown by reducing adipocyte-specific expression of LPL and PPAR- $\gamma$ and by decreasing the number of lipid droplets. This study also demonstrated that seven-day exposure to $0.5 \mathrm{~T}$ SMF reduced the ALP activity and osteogenic marker genes such as SPP and OSX and inhibited the osteogenic differentiation of ASCs. With respect to effects of moderate intensity SMF on ASCs' induction differentiation, published reports are conflicting. Schäfer et al. reported that exposition to $0.6 \mathrm{~T}$ SMF leads to a reduced expression ALP under osteogenic induction, indicating an impairment of osteogenic differentiation of BMSCs and SPIO-labeled BMSCs [30]. However, they also reported that exposition to $0.6 \mathrm{~T}$ SMF over 24 hours significantly promoted the expression of LPL and PPAR $-\gamma$ in BMSCs and SPIO-labeled BMSCs, indicating an enhancement of adipogenesis of BMSCs under the exposure of SMF [30]. For the most part, our result is contrary to previous studies showing that MF exposure accelerates the osteogenic differentiation of SCs. Kim et al. showed that moderate intensity SMF, especially at $15 \mathrm{mT}$, promoted osteoblastic differentiation of MSCs, by upregulating genes associated with mineralization and calcium-banding proteins [31]. Amin et al. reported that a $0.4 \mathrm{~T}$ SMF applied for 14 days elicited a strong chondrogenic differentiation in cultured BMSCs [32].

The influence of MF on living cells depends on cell type, cell line, strength of the MF, and time of exposure. Increasing of SMF intensity or exposure time was associated with progressive decline in proliferation or viability rate in SCs and cancer cells $[19,20]$. This discrepancy in cell type, intensity of SMF, and exposure time might explain the difference between our findings and previous ones. This study found that the $0.5 \mathrm{~T}$ SMF exposure for seven days could impair the biological properties and beneficial function of ASCs and ${ }_{\text {SPIO }}$ ASCs. The SMF induction value and exposure time are two critical factors to affect the biological behavior of SCs. Magnetic targeting techniques have been reported to enhance cell retention, engraftment, and functional benefit of iron-labeled stem cells by 10 -minute or 24-hour exposure to 1.3 T SMF $(6,7), 24$-hour exposure to 0.1 T SMF (8), and 24hour exposure to $0.6 \mathrm{~T}$ SMF (9) in infracted hearts. Further optimization is needed to identify the best magnetic strength and duration for effective targeting. However, this study indicated that simultaneously increasing SMF strength and exposure time might enhance the targeting effect but impair the biological activity and therapeutic efficacy of implanted SCs during magnetic targeting.

\section{Conclusions}

In summary, exposure to 0.5 T SMF over seven days exerted the inhibitory effect on viability, proliferation, cytokine secretion, the expression of surface antigens and stem cell specific markers, and adipogenic and osteogenic differentiation but did not cause DNA damage in ASCs and ${ }_{\text {SPIO }}$ ASCs.

\section{Conflict of Interests}

The authors declare that there is no conflict of interests regarding the publication of this paper.

\section{Acknowledgments}

This work was supported by the National Natural Sciences Foundation of China [81200105], the Natural Science Foundation of Hubei Province of China [2015CFB457], the China Postdoctoral Science Foundation Funded Project [20100470050], Canadian Institute of Health Research (CIHR), and National Research Council of Canada (NRC).

\section{References}

[1] D. Hou, E. A.-S. Youssef, T. J. Brinton et al., "Radiolabeled cell distribution after intramyocardial, intracoronary, and interstitial retrograde coronary venous delivery: implications for current clinical trials," Circulation, vol. 112, no. 9, pp. I150-I156, 2005.

[2] S.-H. Li, T. Y. Y. Lai, Z. Sun et al., "Tracking cardiac engraftment and distribution of implanted bone marrow cells: comparing intra-aortic, intravenous, and intramyocardial delivery," Journal of Thoracic and Cardiovascular Surgery, vol. 137, no. 5, pp. 12251235.e1, 2009.

[3] T. Yasuda, R. D. Weisel, C. Kiani, D. A. G. Mickle, M. Maganti, and R.-K. Li, "Quantitative analysis of survival of transplanted smooth muscle cells with real-time polymerase chain reaction," Journal of Thoracic and Cardiovascular Surgery, vol. 129, no. 4, pp. 904-911, 2005.

[4] J. Terrovitis, R. Lautamäki, M. Bonios et al., "Noninvasive quantification and optimization of acute cell retention by in vivo positron emission tomography after intramyocardial cardiacderived stem cell delivery," Journal of the American College of Cardiology, vol. 54, no. 17, pp. 1619-1626, 2009.

[5] C. J. Teng, J. Luo, R. C. J. Chiu, and D. Shum-Tim, "Massive mechanical loss of microspheres with direct intramyocardial injection in the beating heart: implications for cellular cardiomyoplasty," Journal of Thoracic and Cardiovascular Surgery, vol. 132, no. 3, pp. 628-632, 2006.

[6] K. Cheng, T.-S. Li, K. Malliaras, D. R. Davis, Y. Zhang, and E. Marbán, "Magnetic targeting enhances engraftment and functional benefit of iron-labeled cardiosphere-derived cells in myocardial infarction," Circulation Research, vol. 106, no. 10, pp. 1570-1581, 2010. 
[7] K. Cheng, K. Malliaras, T.-S. Li et al., "Magnetic enhancement of cell retention, engraftment, and functional benefit after intracoronary delivery of cardiac-derived stem cells in a rat model of ischemia/reperfusion," Cell Transplantation, vol. 21, no. 6, pp. 1121-1135, 2012.

[8] A. Chaudeurge, C. Wilhelm, A. Chen-Toumoux et al., "Can magnetic targeting of magnetically labeled circulating cells optimize intramyocardial cell retention?" Cell Transplantation, vol. 21, no. 4, pp. 679-691, 2012.

[9] Z. Huang, Y. Shen, A. Sun et al., "Magnetic targeting enhances retrograde cell retention in a rat model of myocardial infarction," Stem Cell Research and Therapy, vol. 4, article 149, 2013.

[10] L. Wang, J. Deng, J. Wang et al., "Superparamagnetic iron oxide does not affect the viability and function of adipose-derived stem cells, and superparamagnetic iron oxide-enhanced magnetic resonance imaging identifies viable cells," Magnetic Resonance Imaging, vol. 27, no. 1, pp. 108-119, 2009.

[11] S. P. Blaber, C. J. Hill, R. A. Webster et al., "Effect of labeling with iron oxide particles or nanodiamonds on the functionality of adipose-derived mesenchymal stem cells," PLoS ONE, vol. 8, no. 1, Article ID e52997, 2013.

[12] J. M. Hill, A. J. Dick, V. K. Raman et al., "Serial cardiac magnetic resonance imaging of injected mesenchymal stem cells," Circulation, vol. 108, no. 8, pp. 1009-1014, 2003.

[13] D. A. De Ugarte, K. Morizono, A. Elbarbary et al., "Comparison of multi-lineage cells from human adipose tissue and bone marrow," Cells Tissues Organs, vol. 174, no. 3, pp. 101-109, 2003.

[14] L. Wang, J. Deng, W. Tian et al., "Adipose-derived stem cells are an effective cell candidate for treatment of heart failure: an MR imaging study of rat hearts," The American Journal of Physiology-Heart and Circulatory Physiology, vol. 297, no. 3, pp. H1020-H1031, 2009.

[15] X. Bai, Y. Yan, Y.-H. Song et al., "Both cultured and freshly isolated adipose tissue-derived stem cells enhance cardiac function after acute myocardial infarction," European Heart Journal, vol. 31, no. 4, pp. 489-501, 2010.

[16] C. Valina, K. Pinkernell, Y.-H. Song et al., "Intracoronary administration of autologous adipose tissue-derived stem cells improves left ventricular function, perfusion, and remodelling after acute myocardial infarction," European Heart Journal, vol. 28, no. 21, pp. 2667-2677, 2007.

[17] A. Chionna, M. Dwikat, E. Panzarini et al., "Cell shape and plasma membrane alterations after static magnetic fields exposure," European Journal of Histochemistry, vol. 47, no. 4, pp. 299308, 2003.

[18] M. Marędziak, K. Marycz, A. Śmieszek, D. Lewandowski, and N. Y. Toker, "The influence of static magnetic fields on canine and equine mesenchymal stem cells derived from adipose tissue," In Vitro Cellular and Developmental Biology-Animal, vol. 50, no. 6, pp. 562-571, 2014.

[19] F. Javani Jouni, P. Abdolmaleki, and M. Movahedin, "Investigation on the effect of static magnetic field up to $15 \mathrm{mT}$ on the viability and proliferation rate of rat bone marrow stem cells," In Vitro Cellular \& Developmental Biology-Animal, vol. 49, no. 3, pp. 212-219, 2013.

[20] A. D. Rosen and E. E. Chastney, "Effect of long term exposure to $0.5 \mathrm{~T}$ static magnetic fields on growth and size of GH3 cells," Bioelectromagnetics, vol. 30, no. 2, pp. 114-119, 2009.

[21] R. R. Raylman, A. C. Clavo, and R. L. Wahl, "Exposure to strong static magnetic field slows the growth of human cancer cells in vitro," Bioelectromagnetics, vol. 17, no. 5, pp. 358-363, 1996.
[22] S. Amara, T. Douki, J.-L. Ravanat et al., "Influence of a static magnetic field $(250 \mathrm{mT})$ on the antioxidant response and DNA integrity in THP1 cells," Physics in Medicine and Biology, vol. 52, no. 4, 2007.

[23] G. Kubinyi, Z. Zeitler, G. Thuróczy et al., "Effects of homogeneous and inhomogeneous static magnetic fields combined with gamma radiation on DNA and DNA repair," Bioelectromagnetics, vol. 31, no. 6, pp. 488-494, 2010.

[24] A. Reddig, M. Fatahi, B. Friebe et al., "Analysis of DNA doublestrand breaks and cytotoxicity after 7 tesla magnetic resonance imaging of isolated human lymphocytes," PLOS ONE, vol. 10, no. 7, Article ID e0132702, 2015.

[25] S. Salerno, A. Lo Casto, N. Caccamo et al., "Static magnetic fields generated by a $0.5 \mathrm{~T}$ MRI unit affects in vitro expression of activation markers and interleukin release in human peripheral blood mononuclear cells (PBMC)," International Journal of Radiation Biology, vol. 75, no. 4, pp. 457-463, 1999.

[26] M.-O. Kim, H. Jung, S.-C. Kim, J.-K. Park, and Y.-K. Seo, "Electromagnetic fields and nanomagnetic particles increase the osteogenic differentiation of human bone marrow-derived mesenchymal stem cells," International Journal of Molecular Medicine, vol. 35, no. 1, pp. 153-160, 2015.

[27] A. Gruchlik, A. Wilczok, E. Chodurek, W. Polechoński, D. Wolny, and Z. Dzierzewicz, "Effects of $300 \mathrm{mT}$ static magnetic field on IL-6 secretion in normal human colon myofibroblasts," Acta Poloniae Pharmaceutica, vol. 69, no. 6, pp. 1320-1324, 2012.

[28] C. Vergallo, L. Dini, Z. Szamosvölgyi et al., "In vitro analysis of the anti-inflammatory effect of inhomogeneous static magnetic field-exposure on human macrophages and lymphocytes," PLoS ONE, vol. 8, no. 8, Article ID e72374, 2013.

[29] C. Aldinucci, J. B. Garcia, M. Palmi et al., "The effect of strong static magnetic field on lymphocytes," Bioelectromagnetics, vol. 24, no. 2, pp. 109-117, 2003.

[30] R. Schäfer, R. Bantleon, R. Kehlbach et al., "Functional investigations on human mesenchymal stem cells exposed to magnetic fields and labeled with clinically approved iron nanoparticles," BMC Cell Biology, vol. 11, article 22, 2010.

[31] E. Kim, R. Leesungbok, S. Lee et al., "Effects of moderate intensity static magnetic fields on human bone marrow-derived mesenchymal stem cells," Bioelectromagnetics, vol. 36, no. 4, pp. 267-276, 2015.

[32] H. D. Amin, M. A. Brady, J.-P. St-Pierre, M. M. Stevens, D. R. Overby, and C. R. Ethier, "Stimulation of chondrogenic differentiation of adult human bone marrow-derived stromal cells by a moderate-strength static magnetic field," Tissue Engineering Part A, vol. 20, no. 11-12, pp. 1612-1620, 2014. 

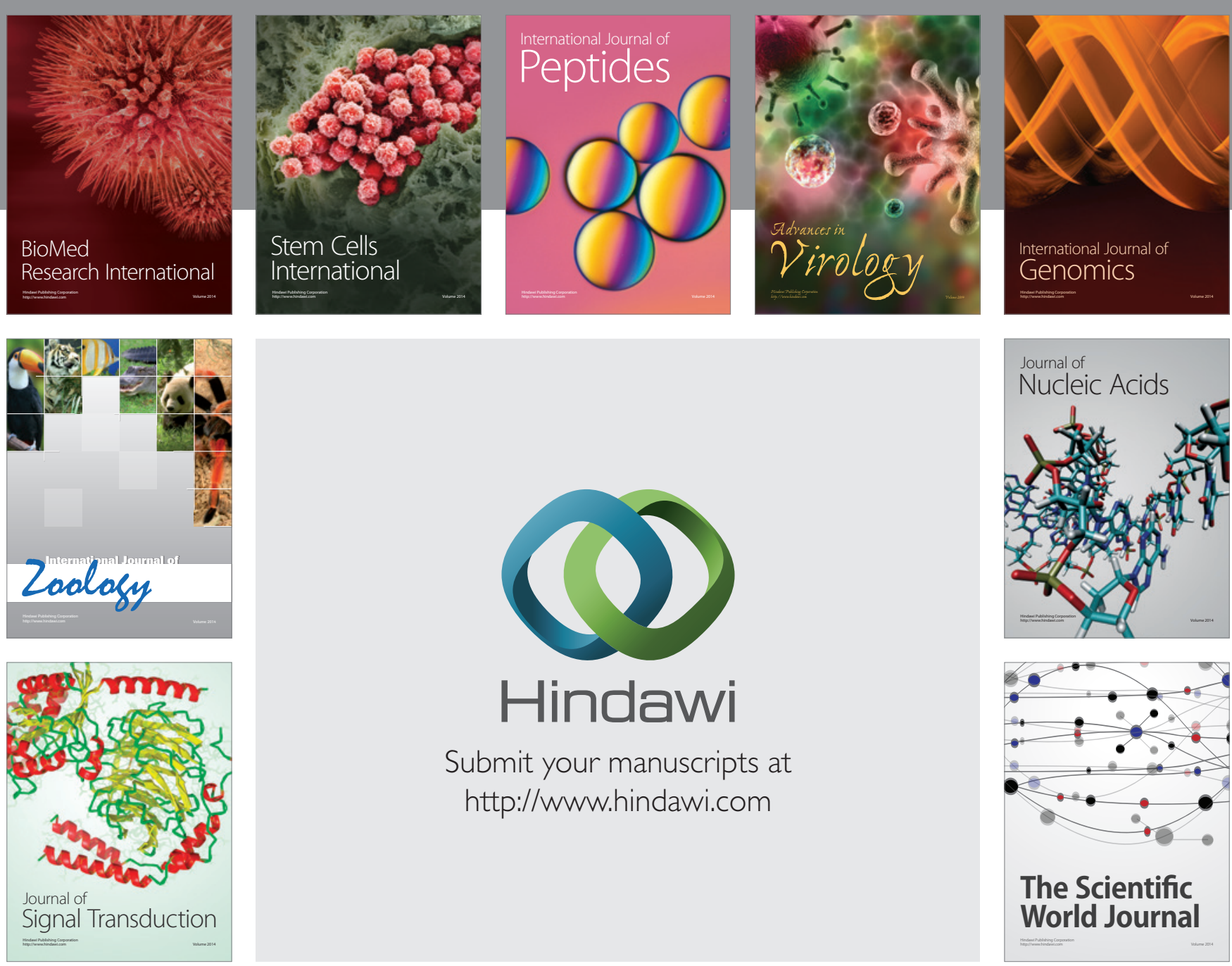

Submit your manuscripts at

http://www.hindawi.com
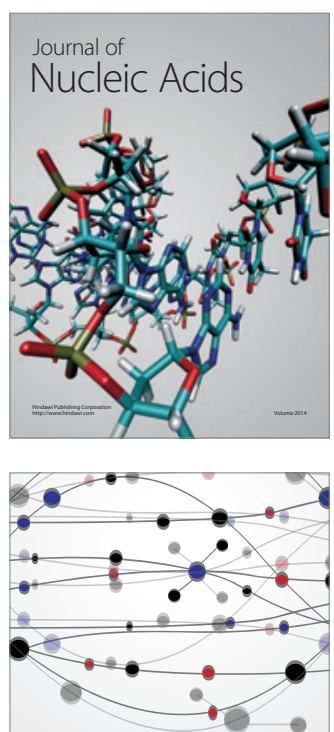

The Scientific World Journal
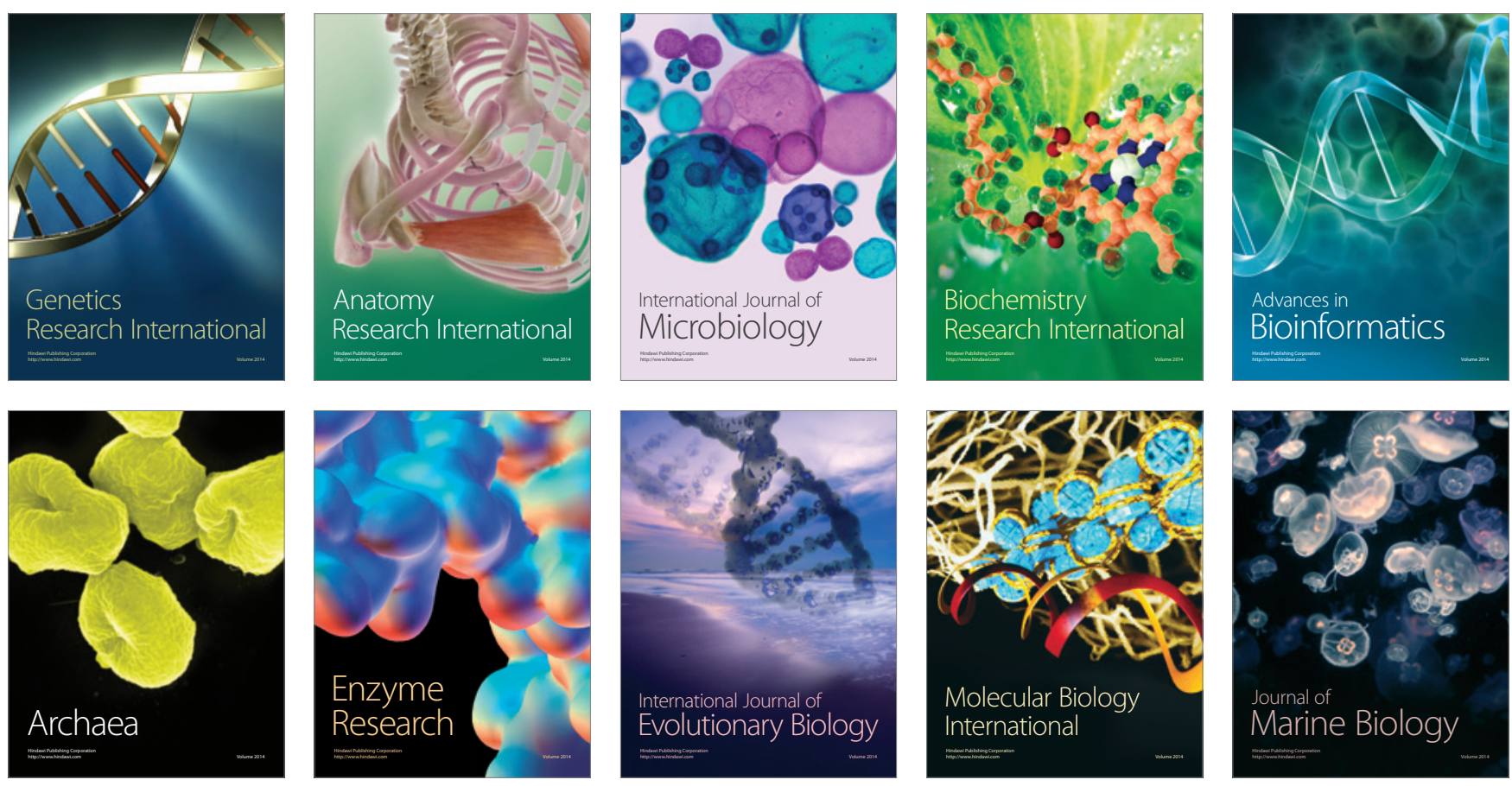